\title{
Layering consideration of FG plates and the calculation of their critical buckling load
}

\author{
Amin Hoseinpour Khoshghalb, Alireza Ahmadi, Reza Dehghani \\ ${ }^{I}$ MSc student of Kerman Technology Higher Education University \\ ${ }^{23}$ Assistant professor of Kerman Technology Higher Education University
}

\begin{abstract}
The aim of this article is the evaluation of P-FGM buckling force with simply supported boundry condition by the ABAQUS software. The FGMs are the improved and novel materials that are microstructurally inhomogeneous and their mechanical properties changes continuously along thickness. Generally these materials made of metal and ceramic composition. The Poison ratio of this plates is constant and supposed that the material properties are changed as a power law function along the plate thickness. The loads are in-plane. The results are compared with analytic results for validation. Then the effect of thickness changing and buckling modes are plotted. Also it can be seen that the behavior of FG plates are similar to Isotropic plates. The results are obtained for the plates of Alminum-Alumina.
\end{abstract}

Keywords: ABAQUS, Material Index, Buckling, FG plate, Critical buckling load.

\section{Introduction}

Along with increasing development of industry, improving the industrial devices and expanding the high power engines in Aerospace industries, Reactors, Turbines and other machines, the materials with high thermal resistance have been identified. In previous years, the net ceramic materials were utilizing in aerospace industry with high performance degree. These materials were good insulations but did not have enough resistance against the residual stresses. Solving this problem, the composite layers were used. On the other hand, the thermal stresses caused the layering phenomenon, due to aforementioned reasons designing a compound material with high thermal and mechanical resistivity found necessity. During the recent years, the different theories have been suggested for plate buckling behavior. The Classic Plate Theory (CPT) showed the acceptable results for thin plates without considering the transverse shear effects. Javaheri and M. R. Eslami 2002, Abrate 2008, Mohammadi and Saidi 2010, Mahdavian 2009, Feldman and Aboudi 1997, Shariat, Javaheri, and Eslami 2005 and Tung and Duc 2010 used this method for the buckling calculation of functionally graded (FG) plates. The First order shear deformation theory (FSDT) evaluates the transvers shear stress along the plate thickness based on Reissner (1945) and Mindlin (1951). But it needs a corection factor to satisfy the lack of transvers shear stress on upper and under surface of plate. Although the FSDT shows the acceptable response for thin and a bit thick plates but it cannot be used simply because of its problem in determining the correction factor. Zhao, Lee, and Liew 2009, Sepiani et al. 2010, Naderi and Saidi 2010, Mohammadi, Saidi, and Jomehzadeh 2010 and Lee, Bae, and Kim 2016 used the FSDT for the FG plate bulcking analyze. Overcoming the FSDT method limitations, the higher order shear deformation theory (HSDT) is used. Javaheri and M. Eslami 2002 calculated the FG plate bulcking force based on HSDT. Mozafari and Ayob 2012 assessed the variable thickness effect on FG plates bulking load. the equations are based on Kirchhoff theory and Sanders nonlinear strain relation.

\section{FG plates}

Functionally graded materials are defined via the volume percentage variation. The Exponential function, or sigmoidal one or power law have been used for explanation of functionally graded material properties. Consider a FG plate that the $\mathrm{x}$ and $\mathrm{y}$ coordinates are given, the coordinate $\mathrm{z}$ is begun from the middle plate towards the thickness. In this plate the properties of material are different from the up and under plates.

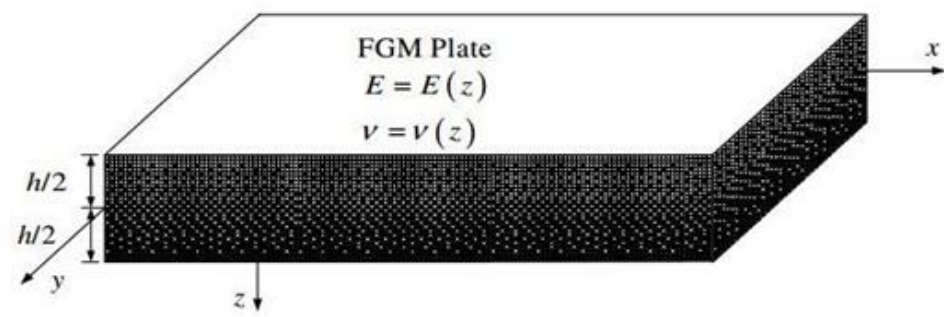

Fig1: The FG plate geometry 
Delale and Erdogan In 1983 showed that the effect of Poisson ratio comparing the Young's modulus is minimal on strain so the Poisson ratio assumed constant for FG plates. Young's modulus along the FG plate's thickness in P-FGM, E-FGM and S-FGM models are Power law, Exponential and sigmoidal bases respectively.

\section{P-FGM Model}

In this situation, the power law function describes the volume percentage, where the $\mathrm{p}$ is material index and $\mathrm{h}$ is the plate thickness.

$$
E(z)=\left(\frac{z+h / 2}{h}\right)^{p} E_{1}+\left[1-\left(\frac{z+h / 2}{h}\right)^{p}\right] E_{2}
$$

E1 and E2 are the Young's modulus in under and upper surfaces respectively. Figure 1 shows the Young's modulus changes in functionally graded materials. It is obvious that for very small or very huge material index the Young's modulus changes rapidly for $\mathrm{z}>0$ near the lower surface and $\mathrm{z}<0$ near the upper surface.

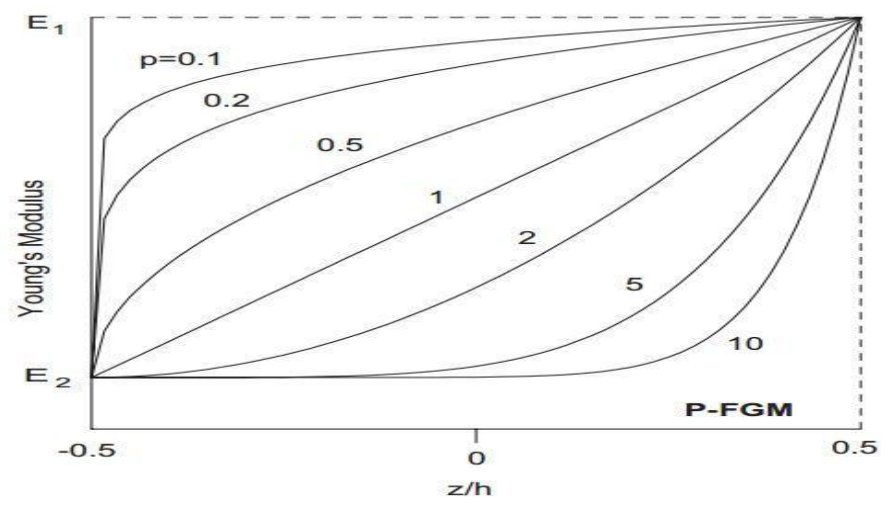

Fig2. P-FGM model

\section{FGM simulation in ABAQUS}

Based on equation 1 the Elasticity Modulus amount for $\mathrm{Al} / \mathrm{Al} 2 \mathrm{O} 3$ along the various thicknesses was driven upon to table 1 . The thickness assumed $1 \mathrm{~mm}$, the Aluminum Elasticity Modulus and the Poisson ratio are 70GP and 0.3 respectively, Elasticity Modulus of Alumina and its Poisson ratio are 380 GP and 0.3 respectively.

Table1. Elasticity Modulus Amount in Various Thicknesses of Al/Al2O3 Plate

\begin{tabular}{|c|c|c|c|c|}
\hline $\mathbf{h}$ & $\mathbf{P = 0 . 5}$ & $\mathbf{P = 1}$ & $\mathbf{P}=\mathbf{1 0}$ & $\mathbf{P}=\mathbf{1 0 0}$ \\
\hline $\mathbf{0 . 5}$ & 70 & 70 & 70 & 70 \\
\hline $\mathbf{0 . 4 5}$ & 77.84 & 85.5 & 194.39 & 378.165 \\
\hline $\mathbf{0 . 4}$ & 85.9 & 101 & $271 / 91$ & 379.992 \\
\hline $\mathbf{0 . 3 5}$ & 94.19 & 116.5 & 318.96 & 380 \\
\hline $\mathbf{0 . 3}$ & 102.72 & 132 & 346.71 & 380 \\
\hline $\mathbf{0 . 2 5}$ & 111.53 & 145.5 & 362.54 & 380 \\
\hline $\mathbf{0 . 2}$ & 120.63 & 163 & 371.2 & 380 \\
\hline $\mathbf{0 . 1 5}$ & 130.07 & 178.5 & 375.82 & 380 \\
\hline $\mathbf{0 . 1}$ & 139.87 & 194 & 378.12 & 380 \\
\hline $\mathbf{0 . 0 5}$ & 150.09 & 209.5 & 379.21 & 380 \\
\hline $\mathbf{0}$ & 160.79 & 225 & 379.69 & 380 \\
\hline $\mathbf{0 . 0 5}$ & 172.04 & 240.5 & 379.891 & 380 \\
\hline $\mathbf{- 0 . 1}$ & 183.93 & 256 & 379.96 & 380 \\
\hline $\mathbf{- 0 . 1 5}$ & 196.06 & 271.5 & 379.99 & 380 \\
\hline $\mathbf{- 0 . 2}$ & 210.206 & 287 & 379.99 & 380 \\
\hline $\mathbf{0 . 2 5}$ & 225 & 302.5 & 380 & 380 \\
\hline $\mathbf{- 0 . 3}$ & 241.36 & 318 & 380 & 380 \\
\hline $\mathbf{- . 3 5}$ & 259.93 & 333.5 & 380 & 380 \\
\hline $\mathbf{- 0 . 4}$ & 281.96 & 349 & 380 & 380 \\
\hline $\mathbf{0 . 4 5}$ & 310.682 & 364.5 & 380 & 380 \\
\hline $\mathbf{- 0 . 5}$ & 380 & 380 & 380 & 380 \\
\hline
\end{tabular}




\section{Plate modelling in ABAQUS}

At first, a plate with dimension based on table 2 was generated and after that, the material based on table 1 elasticity modulus was made. a composite plate with 20 layer was considered and layers divided in equal parts. The load type is buckling and the load was selected as shell edge. Finaly the surface was meshed.

\section{Obtained results of ABAQUS and its compareing with analytic solution}

The results are compared with analytic results (Thai and Choi 2012) for validation. For Simplifying the problem in table 2 the critical buckling load turned dimensionless and the number of layers considered 20.

$$
\bar{N}=N_{c r} \frac{a^{2}}{E_{m} h^{3}}
$$

Where Ncr is the critical buckling force and Em is the Elasticity modulus of Aluminum.

Table2. Comparing the non-dimensional critical buckling loads of Al/Al2O3 plate

\begin{tabular}{|c|c|c|c|c|c|c|}
\hline $\mathbf{a} / \mathbf{b}$ & $\mathbf{a} / \mathbf{h}$ & source & 0 & 0.5 & p & 10 \\
\hline \multirow{6}{*}{0.5} & 5 & ABAQUS & 6.28 & 3.16 & 3.13 & 4.97 \\
\hline & & Analytic & 6.72 & 4.42 & 3.41 & 1.92 \\
\hline & 10 & ABAQUS & 7.14 & 3.71 & 3.49 & 5.5 \\
\hline & & Analytic & 7.40 & 4.82 & 3.71 & 2.18 \\
\hline & 100 & ABAQUS & 7.63 & 3.99 & 3.7 & 5.91 \\
\hline & & Analytic & 7.66 & 4.96 & 3.82 & 2.29 \\
\hline \multirow{6}{*}{1} & 5 & ABAQUS & 14.22 & 7.54 & 7.13 & 11.24 \\
\hline & & Analytic & 16.02 & 10.62 & 8.22 & 4.48 \\
\hline & 10 & ABAQUS & 17.25 & 9.26 & 8.45 & 13.35 \\
\hline & & Analytic & 18.57 & 12.12 & 9.33 & 5.45 \\
\hline & 100 & ABAQUS & 19.62 & 10.51 & 9.45 & 14.95 \\
\hline & & Analytic & 19.61 & 12.71 & 9.77 & 5.87 \\
\hline
\end{tabular}

Plate with material index zero $(\mathrm{p}=\mathbf{0})$

In this state the obtained results of ABAQUS are closer to analytic solution, when then a/h ratio decreases, the amount of non-dimensional critical buckling load calculated by ABAQUS gets far from the analytic amount. The most amunt of error occurs when the $\mathrm{a} / \mathrm{h}=5$, the originated error maybe origins from the ABAQUS weakness.

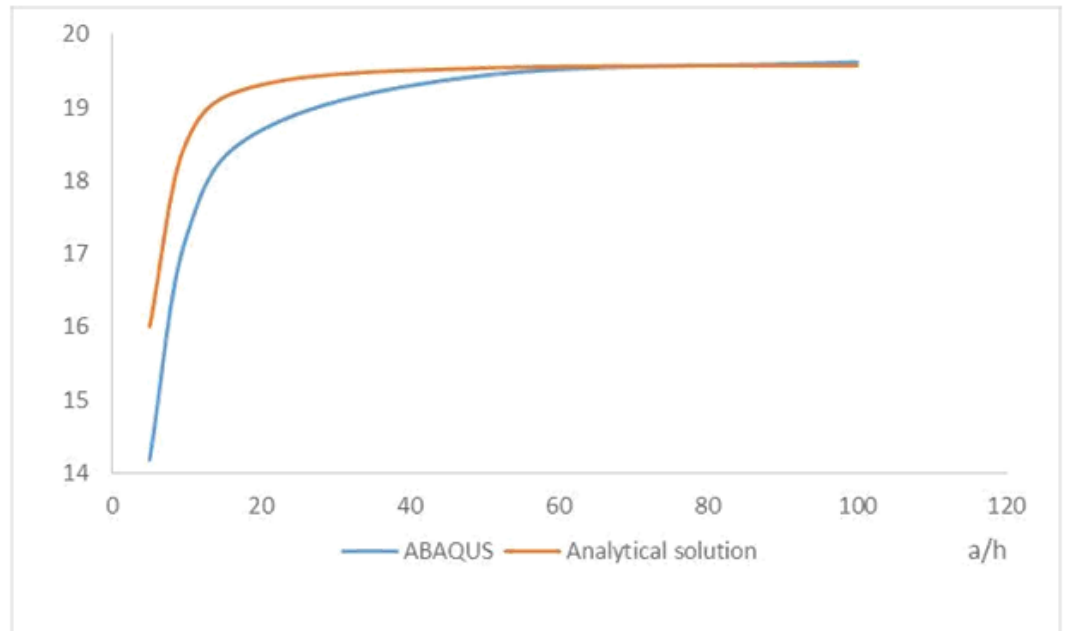

\section{Graph1. The effect of a/h ratio changes on non-dimensional critical buckling load (N)}

Considering the graph 1 , increasing the $\mathrm{a} / \mathrm{h}$, the critical buckling load increases and when the plate are thinner the results close to the analytic solution.

\section{Plate with material index $0.5(p=0.5)$}

When the $\mathrm{p}<1$ the changes nearby the ceramic surface is more and when $\mathrm{p}>1$ the changes near the metal surface is more. Considering that, ABAQUS cannot calculate the critical buckling load and this weakness will be more obvious when the $\mathrm{a} / \mathrm{h}$ ratio be more. 


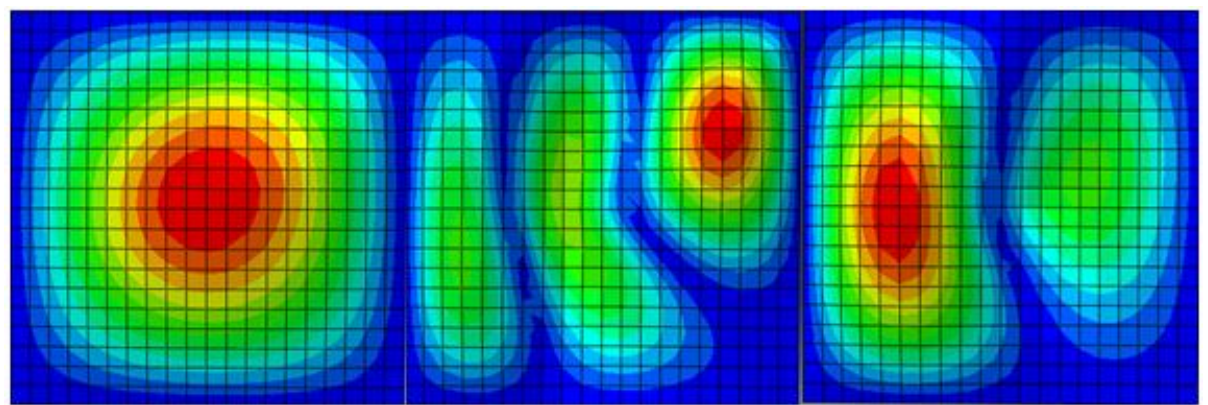

Fig3. The first to third buckling modes for FG plate $\left(\frac{a}{b}=1, \frac{a}{h}=100, p=0.5\right)$

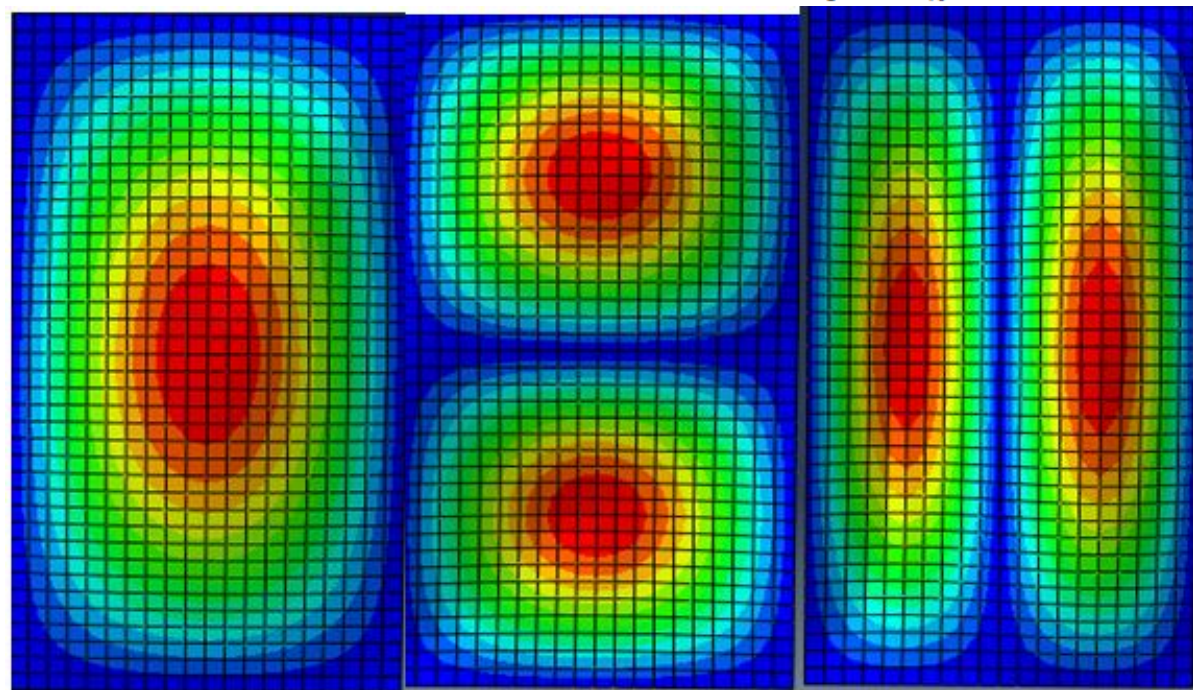

Fig4. The first to third buckling modes for FG plate $\left(\frac{a}{b}=1, \frac{a}{h}=100, p=0.5\right)$

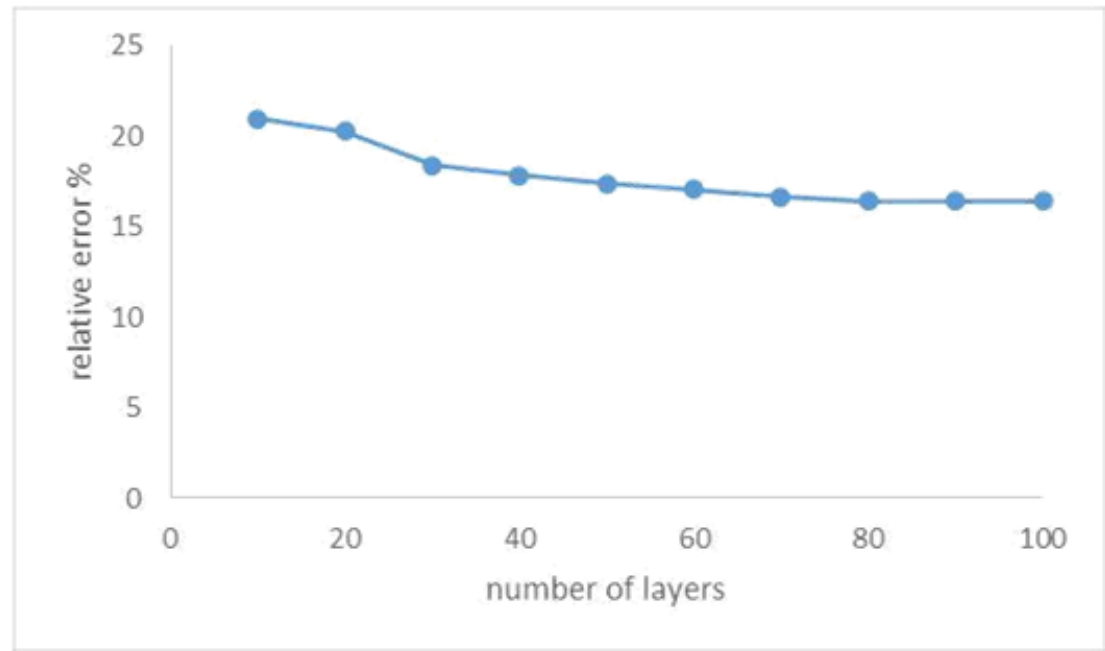

Graph2. Changes of relative error in consequence of layer increasing in ABAQUS ( $\frac{a}{b}=1, \frac{a}{h}=100, p=0.5$ )

In graph 2 changes of relative error versus increasing number of layers was shown. The relative error changed only $3 \%$ With increasing number of layers up to 100 . 


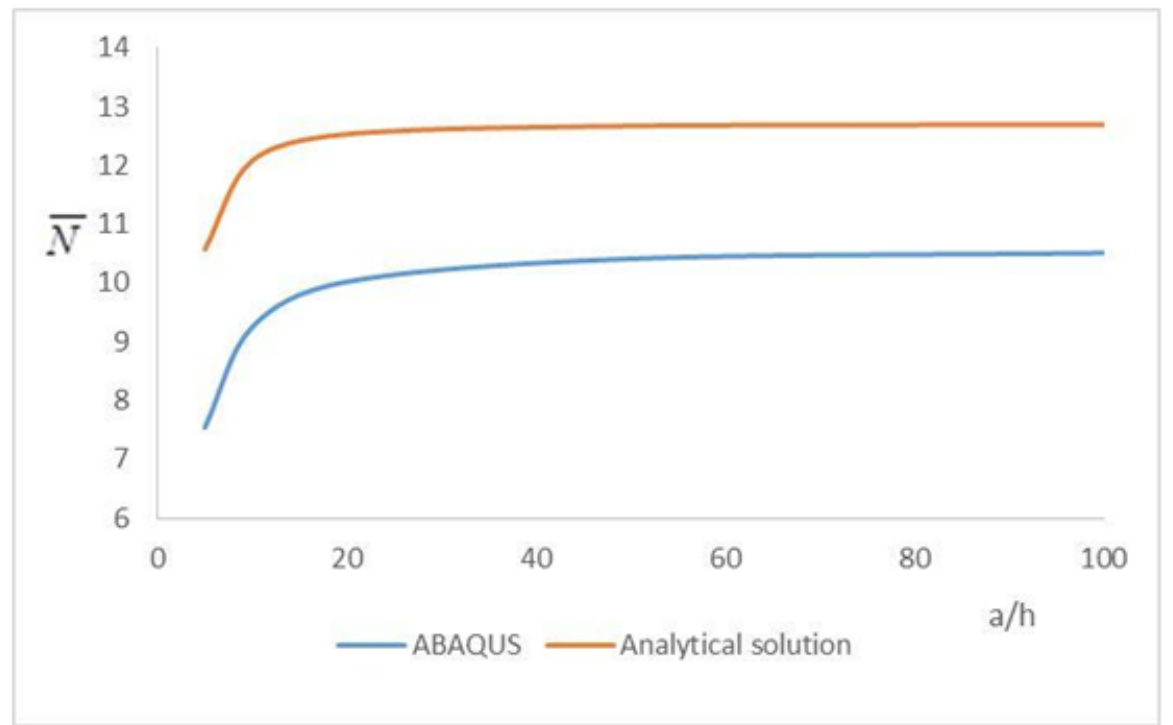

Graph3. The effect of $a / h$ changes on critical buckling force $N(p=0.5)$

Graph three shows the non-dimensional critical buckling load based on thickness changes for both analytic and ABAQUS methods. The trend of them are same although ABAQUS results have error.

\section{Plate with material index $1(\mathrm{p}=1)$}

Given amounts in table 2 shows, that critical buckling load for a plate with material index equal to one has been obtained with a good approximation. It can be concluded that when the FGM changes are linear, the amount of critical buckling load can be calculated, assuming that the plates are layered.

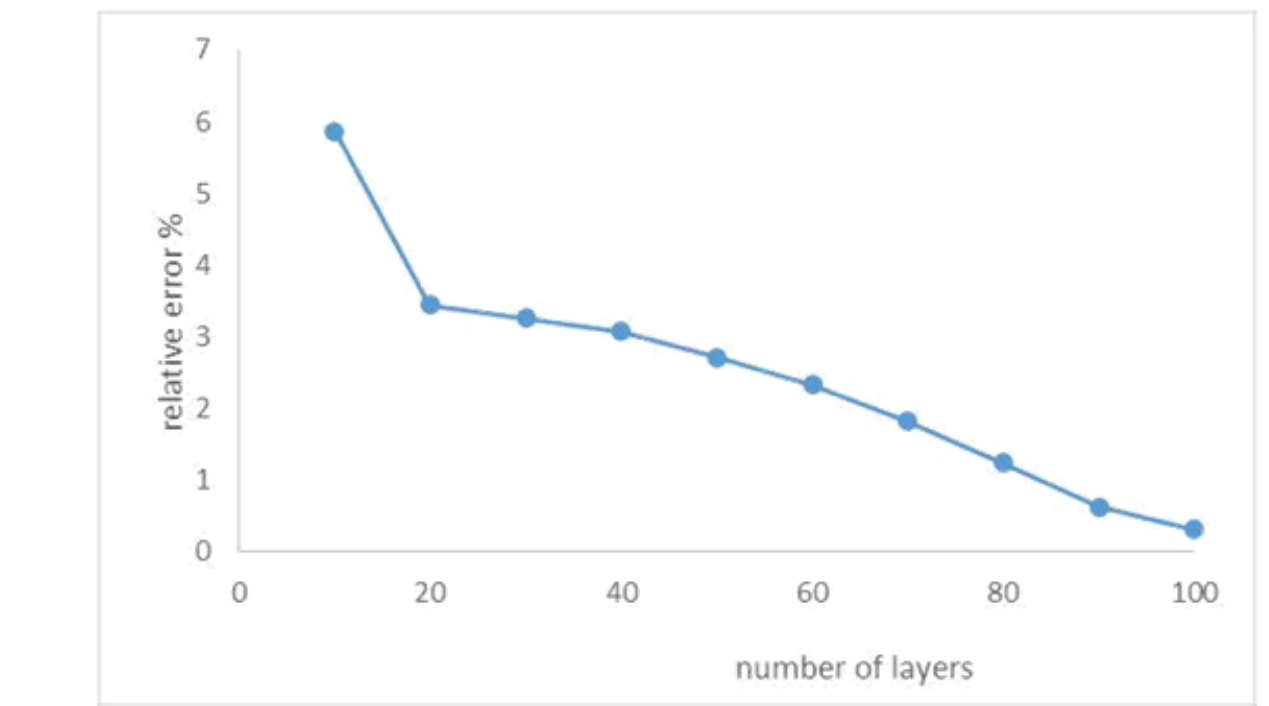

Graph4. Changes of relative error in consequence of layer number increasing in ABAQUS $\left(\frac{a}{b}=1, \frac{a}{h}=100, p=1\right)$

Graph four shows that the ABAQUS results get closer to the analytic amounts, increaing the layer numbers. Ignoring the error reduction along with layer No. increasing the ABAQUS calculations can be used and refernced when the $\mathrm{p}=1$. 


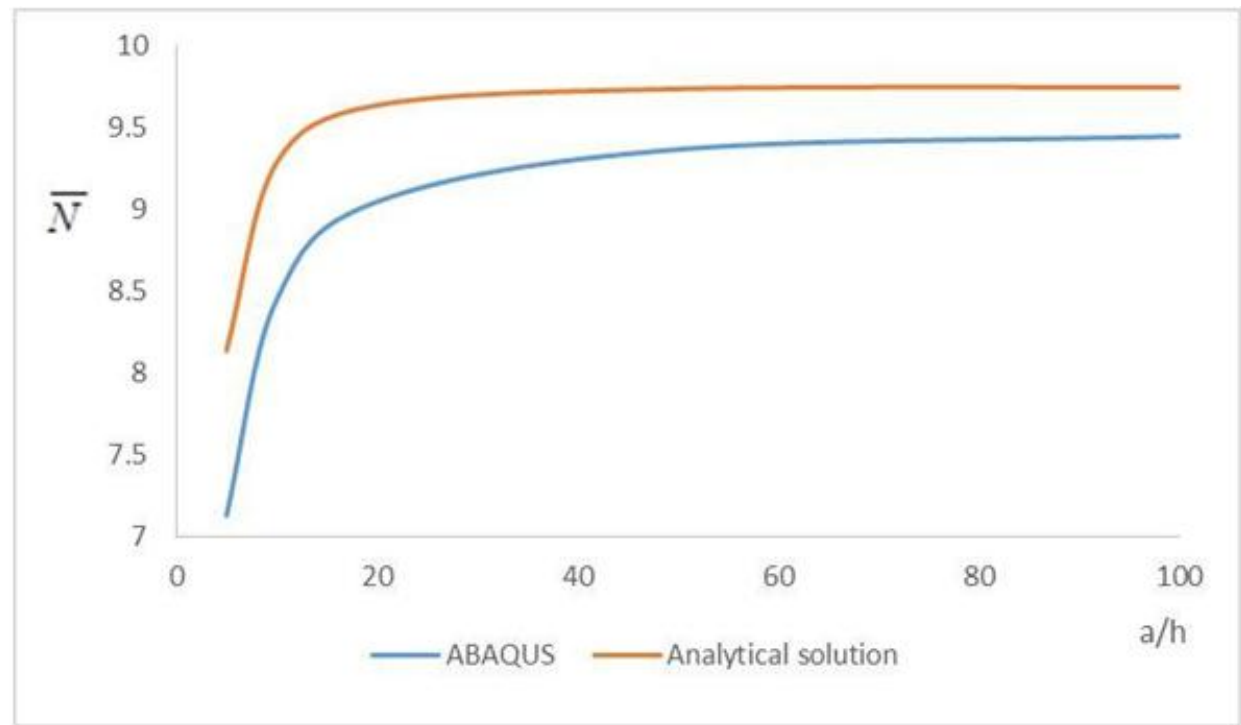

Graph5. The effect of a/h changes on critical buckling load $N(p=1)$.

In graph five the non-dimensional critical buckling load and obtained error of ABAQUS method will increase in consequence of thickness reduction.

Plate with material index 10 ( $p=10)$

Increasing in $p$ amount the changes of elasticity modulus will be faster which causes the hyperactive changes in tiny thicknesses and the error will increase extremely.

Even the error did not reduce consider

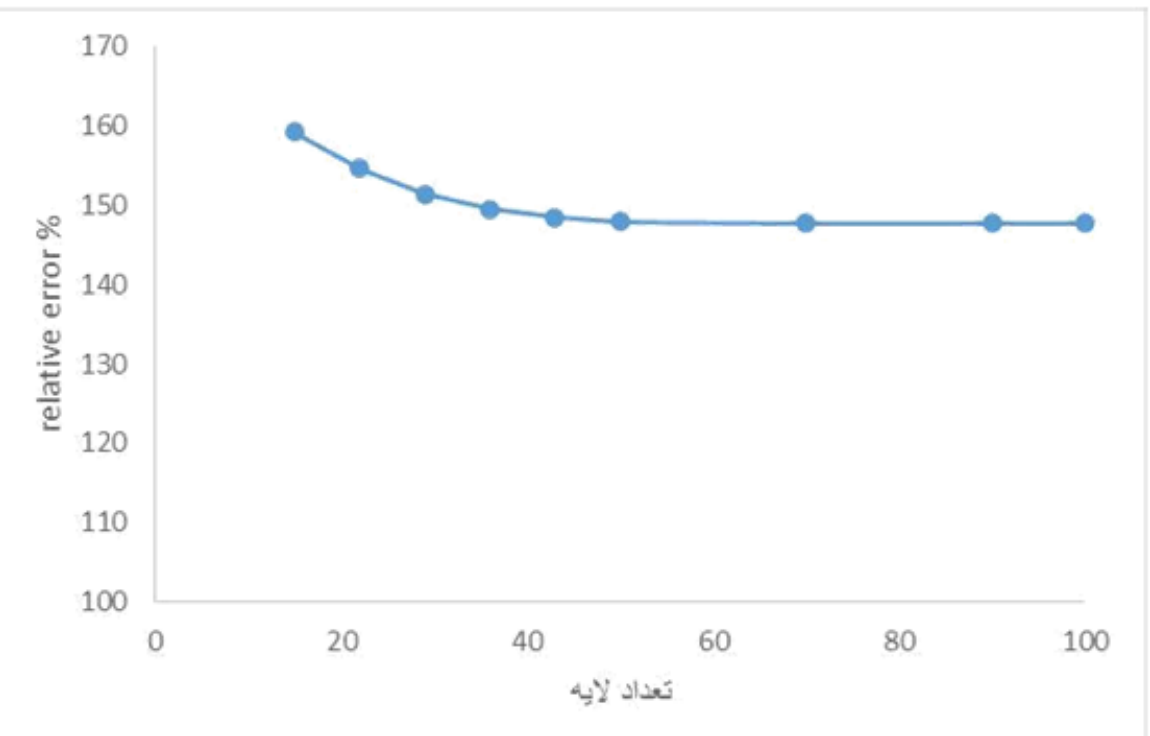

Graph6. Changes of relative error in consequence of layer number increasing in ABAQUS $\left(\frac{a}{b}=1, \frac{a}{h}=100, p=10\right)$ 


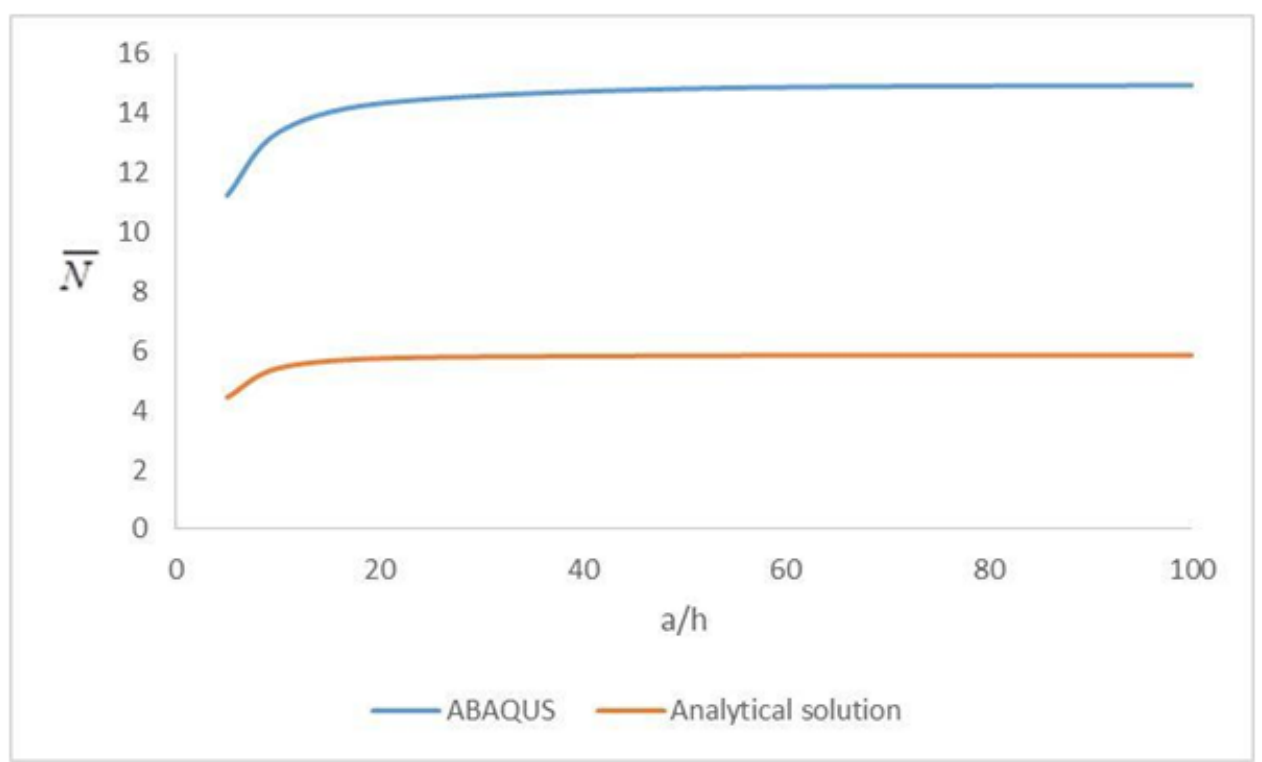

\section{Graph7. The effect of $a / h$ changes on critical buckling force $(p=10)$}

Graph 7 also shows that ABAQUS, forecasted truly the buckling force change along with thickness reduction, but the error is more than other models. It should be considered that in all FG plates same as Ceramic plates the buckling critical force increases in consequence of thickness reduction.

\section{Conclusion}

The obtained results compared with analytical results and presence errors calculated. Upon to results it understood that ABAQUS can calculate the FG plates buckling when the material Elasitcity modulus changes linear. But the higher changes will cause the more errors. In presented error in this article, layered FG plate assuming in ABAQUS does not give the precise results and the ABAQUS cannot be used as a reasonable tool for calculation of critical buckling FG plates. Therefore it suggested that analytical methods and numerical methods utilize for FG plates and more complex models respectively.

\section{References}

[1]. Abrate, Serge. 2008. "Functionally Graded Plates Behave like Homogeneous Plates." Composites part B: engineering Vol. 39 No. 1. 151-58.

[2]. Delale, F. and F. Erdogan. 1983. “The Crack Problem for a Nonhomogeneous Plane.” Journal of Applied Mechanics No. 3. 609-14.

[3]. Feldman, E. and J. Aboudi. 1997. "Buckling Analysis of Functionally Graded Plates Subjected to Uniaxial Loading." Composite Structures Vol. 38. No. 1. 29-36.

[4]. Javaheri, R. and M. R. Eslami. 2002. "Buckling of Functionally Graded Plates under In plane Compressive Loading." ZAMM Journal of Applied Mathematics and Mechanics/Zeitschrift für Angewandte Mathematik und Mechanik Vol. 82. No. 4. $277-83$.

[5]. Javaheri, R. and MR Eslami. 2002. "Thermal Buckling of Functionally Graded Plates Based on Higher Order Theory." Journal of thermal stresses Vol. 25. No. 7. 603-25.

[6]. Lee, Young Hoon, Seok In Bae, and Ji Hwan Kim. 2016. "Thermal Buckling Behavior of Functionally Graded Plates Based on Neutral Surface.” Composite Structures Vol. 137. 208-214.

[7]. Mahdavian, M. 2009. "Buckling Analysis of Simply-Supported Functionally Graded Rectangular Plates under Non-Uniform in-Plane Compressive Loading." Journal of Solid Mechanics Vol. 1. No. 3. 213-25.

[8]. Mindlin, RD. 1951. "Influence of Rotary Inertia and Shear on Flexural Motions of Isotropic Elastic Plates."Journal of Applied Mechanics Vol. 18. 31-38.

[9]. Mohammadi, M. and AR Saidi. 2010. "A Novel Analytical Approach for the Buckling Analysis of Moderately Thick Functionally Graded Rectangular Plates with Two Simply-Supported Opposite Edges.” Proceedings of the Vol. 9. No. 224. $1831-41$.

[10]. Mohammadi, Meisam, Ali Reza Saidi, and Emad Jomehzadeh. 2010. "Levy Solution for Buckling Analysis of Functionally Graded Rectangular Plates." Applied Composite Materials Vol. 17.No 2. 81-93.

[11]. Mozafari, H. and A. Ayob. 2012. "Effect of Thickness Variation on the Mechanical Buckling Load in Plates Made of Functionally Graded Materials." Procedia Technology Vol. 1. 496-504.

[12]. Naderi, A. and AR Saidi. 2010. "On Pre-Buckling Configuration of Functionally Graded Mindlin Rectangular Plates." Mechanics Research Communications Vol. 37. No. 6. 535-38.

[13]. Reissner, E. 1945. "The Effect of Transverse Shear Deformation on the Bending of Elastic Plates." J. appl. Mech No. 2. 6977.

[14]. Sepiani, HA, A. Rastgoo, F. Ebrahimi, and AG Arani. 2010. "Vibration and Buckling Analysis of Two-Layered Functionally Graded Cylindrical Shell, Considering the Effects of Transverse Shear and Rotary Inertia." Materials \& 
Design Vol. 17. No. 3. 176-82

[15]. Shariat, BAS, R. Javaheri, and MR Eslami. 2005. "Buckling of Imperfect Functionally Graded Plates under in-Plane Compressive Loading." Thin-walled structures Vol. 43. No. 7. 1020-36.

[16]. Thai, Huu Tai and Dong Ho Choi. 2012. "An Efficient and Simple Refined Theory for Buckling Analysis of Functionally Graded Plates." Applied Mathematical Modelling 36(3):1008-22.

[17]. Tung, H. Van and ND Duc. 2010. "Nonlinear Analysis of Stability for Functionally Graded Plates under Mechanical and Thermal Loads." Composite Structures Vol. 92. No. 5.1184-91.

[18]. Zhao, X., YY Lee, and KM Liew. 2009. "Mechanical and Thermal Buckling Analysis of Functionally Graded Plates." Composite Structures Vol. 90. No. 2. 161-71. 